\title{
Assessment of Magnitude of Consistent Condom Use and Associated Factors Among Police Force at Riot Control, Addis Ababa, Ethiopia: A Cross-Sectional Study
}

This article was published in the following Dove Press journal: HIVIAIDS - Research and Palliative Care

\author{
Trhas Tadesse (D) \\ Tesfaye Zewdu ${ }^{2}$ \\ Frew Tadesse ${ }^{3}$ \\ Getabalew Endazenaw' \\ Tadesse Alemu (iD) ${ }^{4}$ \\ 'Department of Public health, Yekatit 12 \\ Hospital Medical College, Addis Ababa, \\ Ethiopia; ${ }^{2}$ Department of Public health, \\ Ethiopian Police University College, \\ Addis Ababa, Ethiopia; ${ }^{3}$ Department of \\ Public health, Jigigiga University, Jigigiga, \\ Ethiopia; ${ }^{4}$ Department of Public health, \\ Universal Medical and Business College, \\ Addis Ababa, Ethiopia
}

Background: Police officers are grouped among the most at-risk population for HIV. Most police officers who are mobile related to work behavior might be at risk of HIV for themselves and/or the main source of infection in transmitting the disease to the police members. So the basic aim of this study was to determine the magnitude of condom use and associated factors among police force riot control in Addis Ababa in September 2015.

Materials and Methods: An institutional-based cross-sectional quantitative survey was conducted among a sample of 400 police officers. The sample size was calculated using a single size proportion formula by considering $52 \%$ prevalence of multiple sexual partners. A systematic random sampling technique was used to get study subjects from the institution. A pretested structured questionnaire was employed to obtain the necessary information after getting both written and verbal consent from the concerned body and study subjects. The collected data were checked for completeness and consistency and was coded before data entry. Data were entered and cleaned analyzed using SPSS statistical package.

Results: Some 379 individuals provided data. Most of the respondents $348(95.3 \%)$ had been sexually active during the past 12 months and $280(84.1 \%)$ of them had more than one sexual partner. Seventy-five $(19.8 \%)$ of the sexually active respondents used condoms consistently in the last 12 months. Had sex after drinking alcohol (adjusted OR=2.23; 95\% CI $(1.08,4.61)$ ), ever used substance (adjusted OR=4.37; 95\% CI $(1.18,16.27)$ ), had sex after consuming substance (Adjusted $\mathrm{OR}=4.37 ; 95 \% \mathrm{CI}(1.18,16.27)$ ) and less education status (adjusted $\mathrm{OR}=0.38 ; 95 \%$ CI $(0.16,0.93)$ ) were significantly associated with inconsistent condom use.

Conclusion: There is a high inconsistency of condom use among federal police riot control. This indicates that the study populations are at higher risk of acquiring HIV infection. Substance use like khat, consuming alcohol, and low educational status was the significant predictor of inconsistent condom use among federal police riot control.

Keywords: risky sexual behavior, HIV/AIDS, police force

\section{Introduction}

HIV/AIDS is a major public health problem; it is both an emergency and a long term development issue. ${ }^{1}$ Since the beginning of the pandemic, AIDS has become the headache of developing and developed countries. In 2015, it was estimated that an average of 2.1 million people was newly infected with HIV. Today on average, some 36.7 million people (range 34.0-39.8 million) are living with HIV, 1.1 million
Correspondence: Trhas Tadesse Email ttrhas@gmail.com 
(range 940,000-1.3 million) people have died of it and approximately 17 million people living with HIV are on antiretroviral treatment. $^{2}$

HIV/AIDS continues to spread in every corner of the globe and no country is immune to it. It is the eighth leading killer worldwide and the leading cause of death in Sub-Saharan Africa in $2017 .^{3}$

AIDS is one of the emerging public health problems that could have an overwhelming effect on the social and economic development of a country like Ethiopia. ${ }^{4}$ Ethiopia is experiencing a huge burden from HIV/AIDS epidemic, in which the prevalence rate among the sexually active adults in the general population has $1.4 \%{ }^{5}$

One of the important components of HIV prevention mechanisms is male and female condom promotion and distribution. It is a key method in the fight against the spread of AIDS. ${ }^{6}$ Despite this, globally consistent condom use rates range from 4 to $52.4 \%$ among young, sexually active individuals. $^{7-11}$

The fact that condoms can save the lives of people is not questionable. Most Military or Police forces living in every country have no other options to condom use for protecting themselves or their sexual partners, wives, or husbands their children from HIV/AIDS infection. ${ }^{12}$ The strategy and policy that focuses on prevention mechanisms for HIV in any country should include condoms otherwise it will be incomplete and ineffective. ${ }^{13}$

Members of Ethiopia military force, not only being part of the community where the epidemic is generalized but also because of their young age, the nature of their profession, and other related factors; are at increased risk of HIV/AIDS. ${ }^{14}$ The available opinions also suggest the fact that staying in the military will increase the risk of being infected by HIV and other STIs. ${ }^{15}$ Therefore, the pandemic may be established to pose a security threat, endangering peace and stability of countries of this region. Without peace and stability; development, democracy, and human rights can never be predicted. ${ }^{16}$

Few studies were carried out to show the level of knowledge attitude practice of HIV/AIDS prevention strategies among the military personnel of Ethiopia 7,17 According to military behavior, those few previous studies are not adequate to show the full picture of the phenomenon, and still, there is a gap in the assessment of consistent condom use among military (police) Personnel of the country, Ethiopia. Therefore, this study aims to determine the consistent condom use and associated factors among police force at riot control Addis Ababa, Ethiopia. The outcome of this study was hopefully used to design effective campaign messages and appropriate strategies to promote condom use among members of the Ethiopian military force.

\section{Materials and Methods Study Area and Period}

Addis Ababa is the capital city of Ethiopia. Different diplomats, embassy chancellery, and residents, including Africa Union found in the capital. There is a need to keep peace and security for different sectors and populations of Ethiopia. For this reason, federal police members are found in Addis Ababa. One of peacekeeping is riot control has a total population of 7389 and the structure is from one to four 'ketene' (administrative division). The number of people in the four 'ketena's' are 1840,1859,1777,1807 respectively. The study was conducted in September 2015.

\section{Study Design}

A quantitative cross-sectional study design was conducted to assess consistent condom use and its associated factors among federal police members at riot cControl in Addis Ababa.

\section{Sample Size and Sampling Method}

The source populations were federal police riot control found in Addis Ababa and the study populations were all federal police riot control selected by systematic random sampling technique who were available at the time of the survey. The exclusion criterion was those participants who refused to accept the consent. A total of 400 samples was determined using single population proportion formula with the following assumptions (level of confidence taken to be $95 \% \mathrm{Z} \alpha / 2$ ), $5 \%$ marginal error, and proportion of $52.6 \%$ high-risk sexual behavior among Harrari police force. ${ }^{7}$ Then population correction formal was applied since the source populations are less than 10,000 and $10 \%$ non-response rate. After having the sampling frame systematic random sampling technique every 18th respondent was used after the sample was allocated proportionally to each "ketena" (administrative division)'. The first unit to be selected was taken at random from among the first " $k$ " units.

\section{Data Collection Method and Tool}

Data was collected using self-administered structured questionnaires. The questionnaire was adopted from different kinds of literature review ${ }^{18,19}$ and comprises four 
sections: socio-demographic characteristics of the participant, substance use and sexual behavior and condom use practice. Data collectors, who completed at least Diploma \& can speak Amharic Language, and are familiar with local customs, was recruited for data collection. One supervisor who has a master's in public health was selected from the Ethiopian University College Health Institution Training Centre. The supervisor and data collectors were trained for one day on the purpose, procedures, techniques, and ways of collecting the data. The questionnaire was initially prepared in English and then translated into Amharic. The Amharic version was again translated back to English by another person to check for any inconsistencies or distortions in the meaning of words and concepts. The questionnaire was pre-tested on 20 respondents of anti-terrorism police force members which are similar to the study subjects and adjustment was made based on the findings before the actual data collection.

\section{Data Analysis Procedures}

The data were checked for completeness, coded, and fed to SPSS version 21.0 and was cleaned for inconsistencies and missing values. Descriptive statistics were computed to determine the rate of consistent condom use and other variables. To check for the presence of a significant association between consistent condom use and independent variables, bivariate analyses were first done and variables with P-value less than 0.2 in the bivariate analysis and those not significant but with previous evidence from literature review indicating a possible association with consistent condom use were included for adjustment in the multivariate model at 95\% CI and P-value (0.05).

\section{Study Variables}

The independent variables were socio-demographic characteristics like age, marital status, educational status, ethnicity, and sexual behaviors like the number of partners, type of sexual partners, risk behaviors: such as alcohol, drug, khat, and other substances abuse and the dependent variable was consistent condom use.

\section{Ethical Consideration}

Ethical clearance was secured from the Ethiopian Police University College of Health Institution. Official permission was obtained from different authorities of the riot ontrol Directorate. The respondents were informed about the objective and purpose of the study and verbal consent and written was obtained from each respondent before data collection. Participants were also informed that they can discontinue or refuse to participate in the study at any time they want. Confidentiality was assured and information was recorded anonymously throughout the study.

\section{Operational Definitions and Measurement \\ Substance Use}

Those police forces who use a substance like khat chewing, alcohol drinking, cigarette smoking, and other drug use that predisposes to inconsistent condom use. In this study substance use was measured by yes or no questions followed by a question with options: at most once a weak, any time if available, two to three a week and every day. In this study, the study participants considered as substance user if at least she or he used a substance once a week. ${ }^{18,19}$

\section{Condom Use}

Those police forces who engage in the complete process of intercourse (vaginal) by putting on a male condom onto a penis or female condom into a vagina to prevent HIV infection. To measure condom use the researchers asked questions with dichotomized responses (yes/no) such as "have you ever used condom?." and the reason for not using condoms. Structured responses were provided for their reasons for not using condoms. These questions were used for validation purposes. ${ }^{20}$

\section{Consistent Condom Use}

Those police forces that use condoms at every single sexual intercourse to prevent HIV in the past 12 months. The options were all the time, some times, rarely and never used at all. In this study, those participants who used condoms all the time they had sex in the last 12 months were classified under the category of consistent condom use. ${ }^{20}$

\section{Sexual Behaviors}

To measure participants' sexual behaviors, the researchers asked questions with dichotomized responses (yes/no) such as: "Have you ever had sexual intercourse?" "If yes, with how many girls/boys have you ever had sex?" Finally, it was also asked questions about the most current or recent sexual behaviors of respondents by asking the following questions: "In the past 12 months, have you engaged in sex with anyone? If yes, with whom did you have sex (category of sexual partner, not name)? "In the last 12 months, with how many girls/boys did you have 
sex?" Three structured-responses were provided for participants to choose from, namely, "regular partner only", "commercial sex worker", "Both". ${ }^{21}$

\section{Regular Sexual Partner}

Those police forces who were married and have a spouse or cohabiting (live together) for more than 12 months.

\section{Non-Regular Sexual Partner}

Those police forces who have sexual partners, who had been together for less than 12 months, were not married had never lived together and those who did payment for sex.

\section{Age}

It was classified as starting from 18-24, 25-30 and 31-35 and greater than $35 .{ }^{22}$

\section{Result}

\section{Socio-Demographic Result}

From the total 400 study participants, only 379 completed the questioner; this makes the response rate $94.8 \%$. The age of the respondents ranges from 18-41 years with a mean \pm SD age of $22.6 \pm 3.80$ years. The majority of the respondents, 344 (90.8\%) were male.

From the total participants, 119 (31.4\%) were Oromo by ethnicity and 210 (55.4\%) were Christians Orthodox by religion. Three hundred nine (81.4\%) of the study participants were grade 12 and below in their educational status. Two hundred eighteen (57.8\%) of the participants were constable in their rank. Two hundred sixty-one $(68.9 \%)$ of the study participants have income ranging from 1200-1500 birr per month (Table 1).

\section{Sexual Behavior of the Respondents}

Three hundred sixty-five (96.3\%) of the respondents had sexual intercourse and majority $302(82.9 \%)$ of them had sexual intercourse with a regular partner for the first time followed by $32(8.8 \%)$ with commercial sex workers and $31(8.7 \%)$ had sex with their wives. Most of the respondents $348(95.3 \%)$ were sexually active during the past 12 months. Two hundred eighty $(84.1 \%)$ of the respondents had more than one partner in the last 12 months and 145 $(43.5 \%)$ of them were commercial workers (Table 2 ).

\section{Alcohol and Substance Use}

Three hundred fifteen $(83.1 \%)$ of the respondents had consumed alcohol. From those, 142

(37.5\%) dunk alcohol at most once a week followed by $125(33 \%)$ drunk alcohol if available. Out of these, 211
Table I Sociodemographic Characteristics of the Respondents Among Federal Police Riot Control in Addis Ababa, Ethiopia, September 2015

\begin{tabular}{|c|c|c|c|}
\hline Variables & Category & Frequency & Percent \\
\hline \multirow[t]{3}{*}{ Age } & $18-24$ & 286 & 75.5 \\
\hline & $25-30$ & 73 & 19.3 \\
\hline & $>30$ & 20 & 5.3 \\
\hline \multirow[t]{2}{*}{ Sex } & Male & 344 & 90.8 \\
\hline & Female & 35 & 9.2 \\
\hline \multirow[t]{5}{*}{ Religion } & Orthodox & 210 & 55.4 \\
\hline & Protestant & 112 & 29.6 \\
\hline & Muslim & 44 & 11.6 \\
\hline & Others(Wakifeta & 13 & 3.4 \\
\hline & \&Catholic) & & \\
\hline \multirow{3}{*}{$\begin{array}{l}\text { Marital } \\
\text { status }\end{array}$} & Never married & 282 & 74.4 \\
\hline & Married & 92 & 24.3 \\
\hline & $\begin{array}{l}\text { Others(Divorce \& } \\
\text { widowed) }\end{array}$ & 5 & 1.3 \\
\hline \multirow{2}{*}{$\begin{array}{l}\text { Educational } \\
\text { status }\end{array}$} & $\leq 12$ th grade & 309 & 81.5 \\
\hline & Diploma and above & 70 & 18.5 \\
\hline \multirow[t]{6}{*}{ Rank } & Constable & 218 & 57.8 \\
\hline & Deputy Sergeant & 58 & 15.3 \\
\hline & Sergeant & 74 & 19.6 \\
\hline & Others(Assistant and chief & 29 & 7.7 \\
\hline & Sergeant,Inspector & & \\
\hline & Commander) & & \\
\hline \multirow{3}{*}{$\begin{array}{l}\text { Monthly } \\
\text { income in } \\
\text { birr }\end{array}$} & $1250-1500$ & 261 & 68.9 \\
\hline & $|50|-2000$ & 70 & 18.5 \\
\hline & $>2001$ & 48 & 12.7 \\
\hline \multirow[t]{5}{*}{ Ethnicity } & Oromo & 119 & 31.4 \\
\hline & SNNP(Southern Nations & 116 & 31.4 \\
\hline & and Nationalities People) & & \\
\hline & Amhara & 110 & 29 \\
\hline & Tigraway/ti & 34 & 9 \\
\hline
\end{tabular}

(67\%) was intoxicated on the last day of sexual intercourse. Majority $115(54.5 \%)$ of these intoxicated had encountered sex without a condom.

Concerning the substance use, 222 (58.6\%) of the respondents consumed substance. The most consumed substance was khat which accounts for $108(48.6 \%)$ followed by cigarette 74 (33.3\%). Seventy-five (33.8\%) encounter sex without condoms because of substance use (Table 3 ).

\section{The Magnitude of Condom Use}

Seventy-five $(19.8 \%)$ of the sexually active respondents have used condoms consistently in the last 12 months (Figure 1). 
Table 2 Sexual Behavior of the Respondents at Federal Police Riot Control in Addis Ababa, Ethiopia in September 2015

\begin{tabular}{|c|c|c|}
\hline Sexual Behavior & Frequency & Percent \\
\hline \multicolumn{3}{|l|}{ Ever had sex } \\
\hline Yes & 365 & 96.3 \\
\hline No & 14 & 3.7 \\
\hline \multicolumn{3}{|l|}{ Had first sexual intercourse with } \\
\hline Regular partner & 302 & 82.9 \\
\hline Commercial sex worker & 32 & 8.8 \\
\hline Both & 31 & 8.7 \\
\hline \multicolumn{3}{|l|}{ Had sex in the last 12 months } \\
\hline Yes & 348 & 95.3 \\
\hline No & 17 & 4.7 \\
\hline \multicolumn{3}{|l|}{$\begin{array}{l}\text { The number of sex partners in the } \\
\text { last } 12 \text { month }\end{array}$} \\
\hline Only one partner & 53 & 15.9 \\
\hline More than one partner & 280 & 84.1 \\
\hline \multicolumn{3}{|l|}{ Used condom in the last 12 months } \\
\hline Yes & 319 & 87.4 \\
\hline No & 46 & 12.6 \\
\hline \multicolumn{3}{|l|}{ Frequency of condom use $(n=365)$} \\
\hline All the time & 75 & 19.8 \\
\hline Sometime & 172 & 45.4 \\
\hline Rarely & 72 & 19.0 \\
\hline Never used at all & 46 & 12.1 \\
\hline \multicolumn{3}{|l|}{ Condom use initiated by $(n=319)$} \\
\hline My self & 192 & 50.7 \\
\hline Partner & 44 & 11.6 \\
\hline Mutual decision & 83 & 21.6 \\
\hline \multicolumn{3}{|l|}{ Got condoms whenever you want } \\
\hline Yes & 331 & 87.3 \\
\hline No & 48 & 12.7 \\
\hline
\end{tabular}

The main reason for not using condoms consistently was reduced sexual pleasure $134(61.1 \%)$, do not trust condom102 (46\%) and I was drunken 87 (38\%) (Figure 2).

\section{Factors Associated with Consistent Condom Use}

Using binary logistic regression an association between consistent condom use and age, marital status, religion, educational status, rank, availability of condom, condom use initiated by, ever consumed alcohol, frequency of alcohol drinking, ever consumed substance, frequency of substance consumption, and had sex after consuming the substance. It was found that educational status, condom use initiation, sex after alcohol consumption, ever consumed substance,
Table 3 Alcohol and Substance Use of the Respondents at Federal Police Riot Control in Addis Ababa, Ethiopia September 2015

\begin{tabular}{|l|l|l|}
\hline Variable & Frequency & $\%$ \\
\hline $\begin{array}{l}\text { Ever consumed alcohol } \\
\text { Yes }\end{array}$ & 315 & \\
No & 64 & 83.1 \\
\hline Frequency of drinking alcohol & & 16.6 \\
At most once a weak & 142 & 45.1 \\
Any time if available & 125 & 33 \\
Two to three a week & 29 & 7.7 \\
Every day & 19 & 6 \\
\hline Had sex after drinking alcohol & & \\
Yes & 211 & 67.0 \\
No & 104 & 33.0 \\
\hline Had sex without a condom & & \\
Yes & 96 & 30.5 \\
No & 219 & 69.5 \\
\hline Ever consumed substance & & \\
Yes & 222 & 58.6 \\
No & 157 & 41.4 \\
\hline Type of substance used & & \\
Khat & 108 & 48.6 \\
Cigarette & 74 & 33.3 \\
Others (Hashish and Shisha) & 40 & 18 \\
\hline Had sex after substance use & 116 & \\
Yes & & 52.8 \\
No & & \\
\hline Encountered sex without a condom \\
after substance use & & \\
\hline
\end{tabular}

frequency of substance consumption, and sex after consuming substance were significantly related to consistent condom use. But after adjusting for potential confounders, condom use was significantly related to educational status, sex after alcohol consumption, ever consumed substance, and had sex after consuming the substance.

Participants with the educational status of secondary school were $62 \%$ less likely to consistently use condoms compared to participants with an educational level of college and above (AOR $=0.38,95 \%$ CI 0.16,0.93). Similarly, respondents who had sex after drinking alcohol were found to be 2.23 times less likely to consistently use condoms (AOR $=2.23,95 \%$ CI: 1.08,4.61). Furthermore, respondents who consumed substance ever were 4.37 times less likely to practice consistent condom use $(\mathrm{AOR}=4.37,95 \%$ CI: 


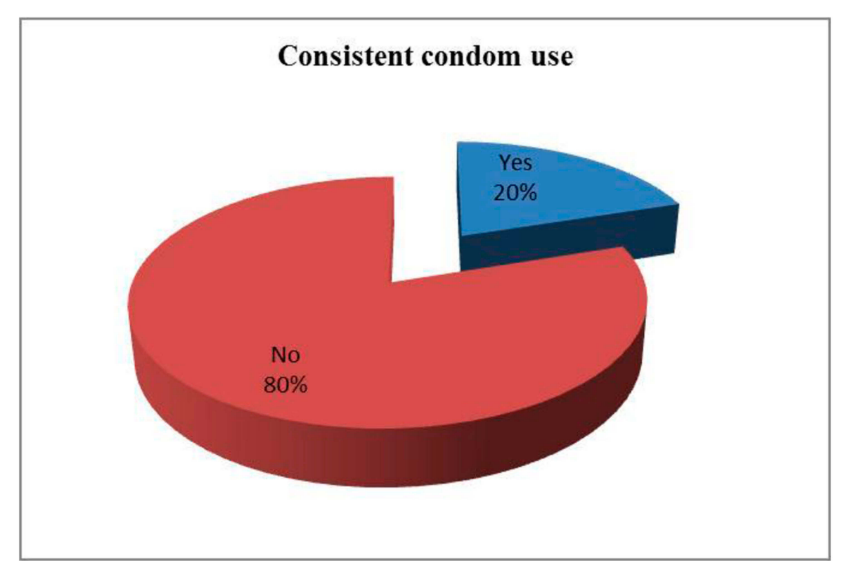

Figure.I Consistent condom use of the respondents at federal police riot control in Addis Ababa, Ethiopia September 2015.

(1.18-16.27). Having sex immediately after substance use was 1.5 times less likely to practice consistent condom use than non-users (Table 4).

But this study found that inconsistent condom use was not significantly associated with marital status, religion, rank, ever consumed alcohol, frequency of alcohol drinking, condom use initiation, availability of condom, and frequency of substance use.

\section{Discussions}

This study provides insight into the magnitude of consistent condom use and associated factors among police force in riot control Addis Ababa.
A condom is widely defined as a physical barrier that can minimize the risk of STIs and HIV infection if the military or police personnel used the condom properly and consistently. ${ }^{23,24}$ Regardless of the different strategies that promote condoms developed in this country, consistent condom use is still low in the police force. ${ }^{25}$ The probable reason for this could be the information provided is not comprehensive enough and has not been tailored to this population as this is explained by this study. The main reasons for not using condoms consistently were reduced sexual pleasure $134(61.1 \%)$, do not trust condom102 (46\%) and I was drunken $87(38 \%)$. And this is similar to the other study done in Kenya. ${ }^{26,27}$

The finding of this study showed that $20 \%$ (95\% CI: $18.6 \%, 25.8 \%$ ) of the participants have used condoms consistently before the survey. This study is similar to the study conducted in Peru among Military and Police Personnel which was the magnitude of condom use was $18.4 \% .{ }^{28}$ The current study was lower than with the study carried out in military personnel in west command Bahir-Dar Ethiopia where the prevalence of consistent condom use with non-regular partners was $59.4 \%,{ }^{22}$ in both Mekele Hospital, Tigray and North West Health center, Amhara region, Ethiopia among people living with HIV/AIDS was $55.7 \%,{ }^{29,30}$ among the troops located in a large cantonment $48.6 \%^{31}$ and $44.9 \%$ among big constriction enterprise workers ${ }^{32}$ and this is

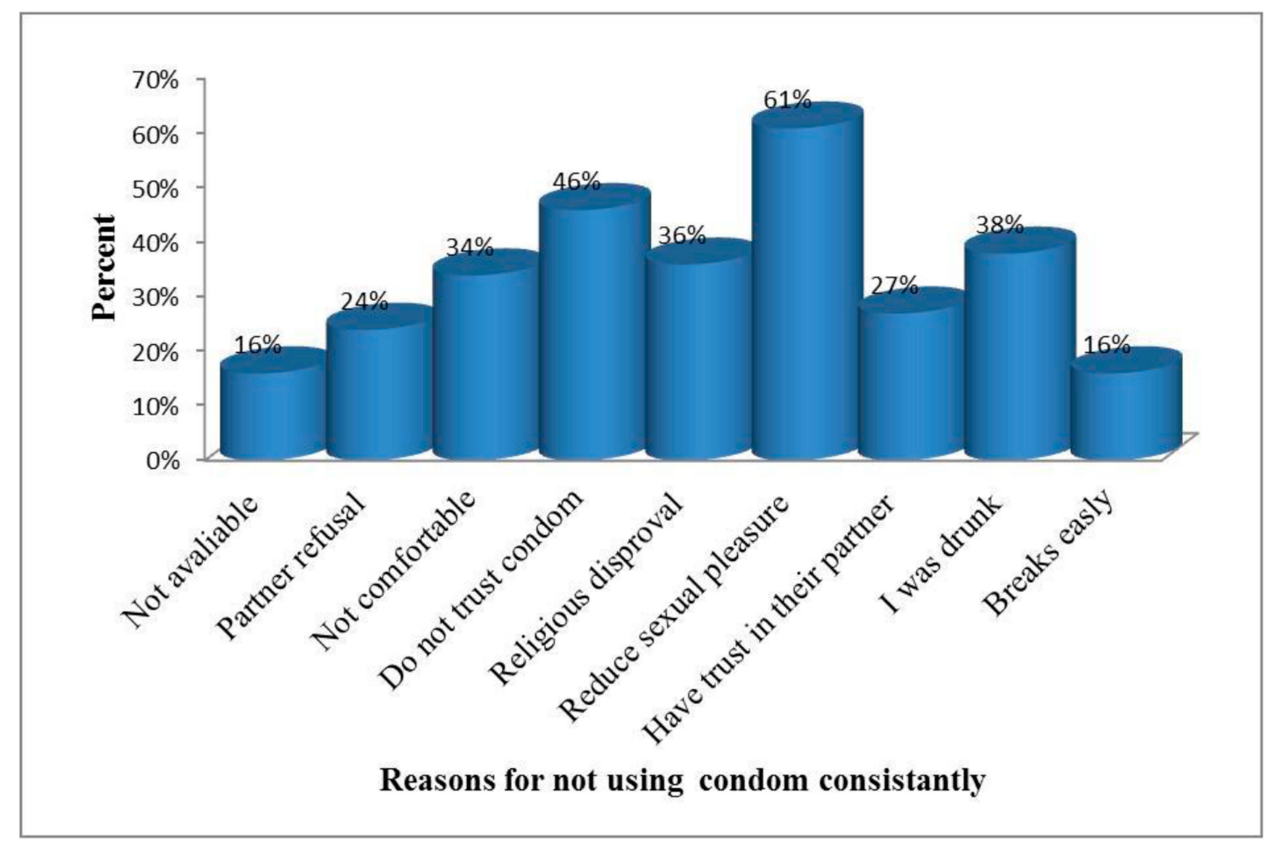

Figure 2 Reasons for not using condoms consistently at federal police riot control in Addis Ababa, Ethiopia September 2015. 
Table 4 Bivariate and Multivariate Analysis of Socio-Demographic and Sexual Behavior of Respondents with Consistent Condom Use at Federal Police Riot Control in Addis Ababa, Ethiopia, September 2015. (* Statistically Significant Factor P<0.2, ** Statistically Significant Factor $\mathrm{P}<0.05$ )

\begin{tabular}{|c|c|c|c|c|}
\hline \multirow[t]{2}{*}{ Variables } & \multicolumn{2}{|c|}{ Consistent Condom Use } & \multirow[t]{2}{*}{ COR (Cl 95\%) } & \multirow[t]{2}{*}{ AOR (Cl 95\%) } \\
\hline & Yes & No & & \\
\hline \multicolumn{5}{|l|}{ Marital status } \\
\hline Never married & 55 & 214 & $1.0(0.58 .1 .82)$ & - \\
\hline Married & 20 & 76 & 1 & \\
\hline \multicolumn{5}{|l|}{ Educational status } \\
\hline Secondary school & 61 & 214 & $0.65(0.34,1.22)^{*}$ & $0.38(0.16,0.93)^{* *}$ \\
\hline College and above & 14 & 76 & I & I \\
\hline \multicolumn{5}{|l|}{ Rank } \\
\hline Constable & 39 & 167 & $1.56(0.47,5.15)$ & - \\
\hline Sargent & 32 & 112 & $1.27(0.38,4.27)$ & - \\
\hline Above Sargent & 4 & $\mathrm{II}$ & 1 & \\
\hline \multicolumn{5}{|l|}{ Condom use initiated by } \\
\hline My self & 33 & 159 & $1.53(0.82,2.86)$ & $\mathrm{I} .08(0.5 \mathrm{I}, 2.30)$ \\
\hline Partner & 22 & 22 & $0.32(0.15,0.69)^{* *}$ & $0.45(0.16,123)$ \\
\hline Mutual decision & 20 & 63 & 1 & 1 \\
\hline \multicolumn{5}{|l|}{ Ever consumed alcohol } \\
\hline Yes & 63 & 246 & $1.07(0.53,2.14)$ & - \\
\hline No & 12 & 44 & 1 & \\
\hline \multicolumn{5}{|c|}{ Had sex after drinking alcohol } \\
\hline Yes & 35 & 176 & $2.0(1.14,3.55)^{* *}$ & $2.23(1.08,4.61)^{* *}$ \\
\hline No & 28 & 70 & 1 & 1 \\
\hline \multicolumn{5}{|l|}{ Ever used substance } \\
\hline Yes & 68 & 154 & $0.12(0.05,0.26)^{* *}$ & $4.37(1.18,16.27)^{* *}$ \\
\hline No & 7 & 136 & 1 & 1 \\
\hline \multicolumn{5}{|l|}{ Frequency of substance use } \\
\hline 2 or more times per week & 22 & 56 & $0.13(0.05,0.32)^{* *}$ & $1.39(0.68,2.85)$ \\
\hline At most once a week & 46 & 98 & $0.11(0.05,0.25)^{* *}$ & $0.99(0.67,3.32)$ \\
\hline Not at all & 7 & 136 & 1 & 1 \\
\hline \multicolumn{5}{|l|}{ Had sex after substance use } \\
\hline Yes & 24 & 82 & $2.09(1.16,3.77)^{* *}$ & $1.5(1.95,3.13)^{* *}$ \\
\hline No & 44 & 72 & 1 & $0.29(0.07,1.17)$ \\
\hline
\end{tabular}

also lower compared to the study done among undergraduate University Students in Southern Ethiopia which was $33.2 \%$ of the students used condom consistently ${ }^{33}$ and $38.6 \%$ among University Students in Nigerian. ${ }^{34}$ This difference might be due to the difference in the study area, period, and source of population.

Furthermore, in the current study, those Police forces with a higher educational status were more likely to use condoms consistently compared to the participants who have lower educational status. This is in line with the study done in northwestern Ethiopia among HIV/AIDS patients receiving antiretroviral therapy. ${ }^{28}$ Unlike the other study done in GamoGofa Zone, South West Ethiopia, ${ }^{33}$ Ethiopian Military personals, ${ }^{21}$ and Ethiopia Harreri police force, ${ }^{7}$ this study failed to demonstrate the significant association between age and consistent condom use. This might be due to most of the study participants found under the same age categories.

This study also showed that, respondents who have ever consumed substance were 4.37 times less likely to practice consistent condom use than those who have ever consumed substance, and having sex immediately after substance use was 1.5 less likely to practice consistent condom use than 
non-users. Similarly, respondents who had sex after drinking alcohol were found to be 2.23 times less likely to use condoms consistently ( $\mathrm{AOR}=2.23,95 \% \mathrm{CI}: 1.08,4.61)$. This is in line with the study done in Semi-Urban Area of the Amhara Region, Ethiopia. ${ }^{34}$ But this is different from the study done in Peru among police and military personnel in which the analysis did not find an association between alcohol consumption before the sexual encounter and condom use. ${ }^{26}$

Unlike in the study conducted in the North West Ethiopian health center, among HIV-positive clients on Antiretroviral Therapy that has reported that the chance of consistent condom use initiated by sex partner was $81 \%$ less likely than condom use initiated by respondent him/herself.35 But the current study field to show the association between condom use initiator and consistent condom use.

\section{Limitations}

- Since the study design was cross-sectional it did not show the cause and effect.

- The study was not used the qualitative method to complement the quantitative.

- It is very difficult to discuss with similar study participants as there is no literature.

\section{Conclusion}

The study confirmed the presence of substantial gaps in inconsistent condom use. The overall magnitude of consistent condom use by the police members were $20 \%$. The main factors that were significantly associated with consistent condom use among riot control, police force were educational status, substance use, and dirking alcohol. However; consistent condom use was not associated with age, marital status, religion, rank, condom use initiator, and availability of condom use.

\section{Recommendation}

Based on the findings of the study and understanding the nature of the police personnel:

The magnitude of inconsistent condom use in the study area was high. Therefore policymakers and concerned bodies should design appropriate sexual education programs and strategies to help the study subjects acquire adequate information about the importance of consistent condom use and hence help them reduce the risk of acquiring HIV infection.

\section{Abbreviations}

AIDS, Acquired Immunodeficiency Syndrome; AOR, Adjusted Odds Ratio; CI, Confidence Interval; COR,
Crude Odds Ratio; HIV, Human Immunodeficiency Virus; STI, Sexual Transmitted Infection.

\section{Data Sharing Statement}

The finding of this study is generated from the data collected and analyzed based on the stated methods and materials. There is no supplementary file. The original data supporting this finding will be available at any time upon request.

\section{Ethics Approval and Consent to Participants}

The study protocol was performed following ethical principles. Approval of institutional review board of Ethiopian police University College was obtained and analysis was conducted on anonymized data.

\section{Acknowledgments}

We would like to express heartfelt thanks to Ethiopian police University College for funding the study. We also wish to express our gratitude to the study participants.

\section{Author Contributions}

All authors contributed to data analysis, drafting or revising the article, gave final approval of the version to be published, and agree to be accountable for all aspects of the work.

\section{Funding}

This study was funded by the research program supported by Police university college Addis Ababa, Ethiopia, and Police University College has no role in the design of the study and collection, analysis, and interpretation of data and in writing the manuscript.

\section{Disclosure}

The authors report no conflicts of interest in this work.

\section{References}

1. Slogrove AL, Sohn AH. The global epidemiology of adolescents living with HIV: time for more granular data to improve adolescent health outcomes. HHS Public Access. 2018;13(3):170-178. doi:10.1097/COH.0000000000000449

2. UNAIDS. Global AIDS update. 2016.

3. The LANCET. Findings from the global burden of disease study. Ins Health Metrics Evaluation. 2017.

4. Shewamene Z, Legesse B, Tsega B, Bhagavathula AS, Endale A. Consistent condom use in HIV/AIDS patients receiving antiretroviral therapy in northwestern Ethiopia: implication to reduce transmission and multiple infections. HIV/AIDS Research and Palliative Care. 2015;119. Dove press. 
5. Girum T, Wasie A, Worku A. Trend of HIV/AIDS for the last 26 years and predicting achievement of the 90-90-90 HIV prevention targets by 2020 in Ethiopia: a time series analysis. BMC Infect Dis. 2018;18(320). doi:10.1186/s12879-018-3214-6

6. Beksinska ME, Smit JA, Mantell JE. Progress and challenges to male and female condom use in South Africa. Sex Health. 2012;1; 51-58. doi:10.1071/SH11011.

7. Argaw R. Harari police force and factors which influence preventive behaviours of HIV/AIDS in the Harari regional state, Ethiopia. Harar Bulletin Health Sci. 2011;1(1):40-49.

8. Tarkang EE. Factors associated with consistent condom use among senior secondary school female learners in Mbonge subdivision of rural Cameroon. J AIDS HIV Res. 2012;5(6):214-223.

9. Wong WCW, Cheng S, Miu HYH, Ong JJ, Chen J, Loper KA. Contextual factors associated with consistent condom use and condom self-efficacy amongst African asylum seekers and refugees in Hong Kong. Infect Dis Health. 2017;23:23-32. doi:10.1016/j. idh.2017.08.006

10. Bryan AE, Norris J, Abdallah DA, et al. Condom-insistence conflict in Women' alcohol-involved sexual encounters with a new male partner. Psychol Women Q. 2017;41(1):100-113. doi:10.1177/ 0361684316668301

11. Nesoff ED, Dunkle K, Lang D. The impact of condom use negotiation self-efficacy and partnership patterns on consistent condom use among college-educated women. Health Educ Behav. 2016;43 (1):61-67. doi:10.1177/1090198115596168

12. Anglewicz P, Clark S. The effect of marriage and HIV risks on condom use acceptability in rural Malawi. SocSci Med. 2013;97. doi:10.1016/j.socscimed.2013.06.024

13. Abera H, Tamiru F, Kibret GD. Intention toward condom use and its associated factors among students of debre work senior secondary and preparatory school, East GojjamZone, Amhara Region, Ethiopia. HIV/ AIDS Res Palliative Care. 2017;9:137-143. doi:10.2147/HIV.S130145

14. Adal M. Systematic review on HIV situation in Addis Ababa, Ethiopia. BMC Public Health. 2019;19; 1544

15. Gottwald C, Schwarz NG, Frickmann H. Sexually transmitted infections in soldiers a cross-sectional assessment in german paratroopers and navy soldiers and a literature review. Eur J Microbiol Immunol. 2019;9(4):138-143. doi:10.1556/1886.2019.00023

16. Hannum H. Reinvigorating human rights for the twenty-first century. Human Rights Law Rev. 2016;Volume 16(Issue 3):409-451. doi:10.1093/hrlr/ngw015

17. Kebede G, Kumsa A, Tafese A, Abdissa S. HIV/AIDS prevention practices among military personnel in Northwest Ethiopia. AIDS Care. 2019; 31(1):1-5. doi:10.1080/09540121.2019.1587362

18. Alebachew W, Semahegn A, Ali T, Mekonnen H. Prevalence, associated factors and consequences of substance use among health and medical science students of Haramaya University, eastern Ethiopia, 2018: a cross-sectional study. BMC Psychiatry. 2019;19:343.

19. Andualem Henock A, Deyessa N, Abajobir AA. Sexual violence and substance use among female students of Mizan-Tepi University, Southwest Ethiopia: a mixed-method study. J Women's Health, Issues Care. 2015;4(4).

20. Conserve D, Sevilla L, Younge S, Mbwambo J, King G. Condom use among HIV-positive sexually active adults and partner's HIV status in dar es Salaam, Tanzania. J Health Care Poor Underserved. 2012;23(1):191-203. doi:10.1353/hpu.2012.0010
21. Alamrew Z, Bedimo M, Azage M. Risky sexual practices and associated factors for hiv/aids infection among private college students in Bahir Dar City, Northwest Ethiopia. Hindawi Publishing Corporation ISRN Public Health. Volume 2013. 9 pages.

22. Alamrew N. The prevalence of consistent condom use among western command force in Bahir -Dar city, North West Ethiopia. Global $J$ Med Res. 2014;14(4):20-23.

23. Villaran MV, Konda K, Bayer A, Mendoza C. Condom use by partner type among military and police personnel in peru. Am j Men's Health. 2012;6(4):266-272. doi:10.1177/1557988311431628

24. Weldesenbet A, Abdosh T, Tefera TK, Ayda R, Hafte K. Sexual risk behavior among military personnel stationed in Eastern Ethiopia: using mixed methods approaches. HIV Curr Res. 2018;3:129. doi:10.4172/2572.08051000129

25. Bain LE, Clovis CN, MuchiDitah C, Ekukwe N, Kongnyuy EJ. Patterns and determinants of consistent condom use among cameroonian soldiers. J Arch Mil Med. 2017;5(2):e57335. doi:10.5812/ jamm. 57335

26. Farrington EM, Bell DC, DiBacco AE. Reasons people give for using (or not using) condoms. AIDS Behav. 2016;20(12):2850-2862. doi:10.1007/s10461-016-1352-7

27. Ngurea K, Mugoa N, Celum C, et al. A qualitative study of barriers to consistent condom use among HIV-1 serodiscordant couples in Kenya. NIH Public Access AIDS Care. 2012;24(4):509-516. doi:10.1080/09540121.2011.613911

28. Apolaya M, Palacios O, Lescano AG, et al. Condom use by partner type among military and police personnel in Peru. Am J Mens Health. 2012;6:266. doi:10.1177/1557988311431628

29. Berhane Y, Kidanemariam A, Debesay B. Consistent condom utilisation and associated factors among people living with HIV/AIDS in Mekele Hospital, Tigray, North Ethiopia. Intl Jl Develop Res. 2015;5 (1):3069-3077.

30. Ali MS, Tegegne ET, Tesemma MK, Tegegne KT. Consistent condom use and associated factors among HIV-positive clients on antiretroviral therapy in North West Ethiopian Health Center, 2016 GC. Hindawi,AIDS Res Treatment. 2019;1:1-10.

31. Saiprasad CG, Banerjee LC, Jadhav LSS, Sahoo MP, Parashar SS, Basannar SD. Behavioural surveillance survey among troops in a large military station. MJAFI. 2003;59:197-201.

32. Kassa M, Alamrew Z. Risky sexual behaviour among big construction enterprise workers; Bahir Dar City, Amhara Regional State, Northwest Ethiopia. Int J Clin Med. 2013;4:296-303. doi:10.4236/ ijcm.2013.46052

33. Gelibo T, Alemayehu A. Consistent condom use and preference of HIV risk preventive interventions among undergraduate university students in Southern Ethiopia: a cross sectional study. J AIDS Clin Res. 2015;6(4).

34. Ajayi AI, Ismail KO, Akpan W. Factors associated with consistent condom use: a cross-sectional survey of two Nigerian universities. BMC Public Health. 2019;19:120. doi:10.1186/s12889-019-7543-1

35. Malaju MT, Asale GA. Association of Khat and alcohol use with HIV infection and age at first sexual initiation among youths visiting HIV testing and counseling centers in Gamo-Gofa Zone, South West Ethiopia. BMC Int Health Hum Rights. 2013;13(10). doi:10.1186/ 1472-698X-13-10 


\section{Publish your work in this journal}

HIV/AIDS - Research and Palliative Care is an international, peerreviewed open-access journal focusing on advances in research in HIV, its clinical progression and management options including antiviral treatment, palliative care and public healthcare policies to control viral spread. The manuscript management system is completely online and includes a very quick and fair peer-review system, which is all easy to use. Visit http://www.dovepress.com/testimonials.php to read real quotes from published authors. 